Meta

Journal des traducteurs

Translators' Journal

\title{
A Psycholinguistic Analysis of Translation Processes
}

\section{Wolfgang Lörscher}

Volume 41, numéro 1, mars 1996

Le(s) processus de traduction / Translation Process(es)

URI : https://id.erudit.org/iderudit/003518ar

DOI : https://doi.org/10.7202/003518ar

Aller au sommaire du numéro

\section{Éditeur(s)}

Les Presses de l'Université de Montréal

\section{ISSN}

0026-0452 (imprimé)

1492-1421 (numérique)

Découvrir la revue

\section{Citer cet article}

Lörscher, W. (1996). A Psycholinguistic Analysis of Translation Processes. Meta, 41(1), 26-32. https://doi.org/10.7202/003518ar
Résumé de l'article

Cet article présente une étude empirique des processus de traduction à partir d'un corpus de traductions. On décrit d'abord la méthodologie utilisée, puis on présente un modèle pour l'analyse des processus de traduction. On compare ensuite les processus utilisés par les traducteurs professionnels et par les non-professionnels et on termine avec des considérations quant aux implications de cette analyse sur l'enseignement de la traduction. 


\title{
A PSYCHOLINGUISTIC ANALYSIS OF TRANSLATION PROCESSES
}

\author{
WOLFGANG LÖRSCHER \\ University of Hildesheim, Hildesheim, Germany
}

\begin{abstract}
Résumé
Cet article présente une étude empirique des processus de traduction à partir d'un corpus de traductions. On décrit d'abord la méthodologie utilisée, puis on présente un modèle pour l'analyse des processus de traduction. On compare ensuite les processus utilisés par les traducteurs professionnels et par les non-professionnels et on termine avec des considérations quant aux implications de cette analyse sur l'enseignement de la traduction.
\end{abstract}

\begin{abstract}
This article, outlines a project in which translation processes are investigated empirically an the basis of a corpus of translations. After a description of the methodology used, a model for the analysis of translation processes is presented followed by a brief comparison of professional and non-professional translation processes. In the concluding section, considerations are made as regards implications of translation process analysis for translation teaching.
\end{abstract}

\section{INTRODUCTORY REMARKS}

The considerations which will be made in this paper fall within the newly established field of translation process analysis ( $c f$. Gerloff 1988; Jääskeläinen 1990; Krings 1986; Lörscher 1991; Séguinot 1989; Tirkkonen-Condit 1991). They are based on a research project which I have been carrying out since 1983 . The aim of this project is to analyze psycholinguistically translation performance as it relates to a corpus of orally produced translations from German into English and vice versa. This is done in order to reconstruct translation strategies. These underlie translation performance, operate within the translation process, and are thus not open to direct inspection. In the first stage of the project, translation processes of advanced foreign language learners were investigated. The results yielded are contained in my monograph Translation Performance, Translation Process, and Translation Strategies. A Psycholinguistic Investigation (Tübingen, 1991). The second stage of the project, in which professional translators' and, later on, bilingual children's translation processes are analyzed, is in progress (Lörscher in preparation).

\section{METHODOLOGY}

As concerns the methodology employed in investigating translation processes, a distinction can be made between methods and procedures for the elicitation of data and those for the analysis and evaluation of data.

\section{Methods for Data Elicitation}

Among the methods for the elicitation of data, the introspective procedure of thinking-aloud (Ericsson and Simon 1984) is of decisive importance. During the last years, a lot has been said and written about the advantages and disadvantages of thinking-aloud. Elsewhere (Lörscher 1991) I put forward seven arguments in favour of this method for 
eliciting information about translation processes. As a conclusion, I pointed out that thinking-aloud is a useful tool for collecting data about mental processes in general, and translation processes in particular, if we take into account the conditions under which the data are externalized and their inherent limitations.

\section{Methods for Data Analysis and Evaluation}

The analysis and evaluation of data is carried out by means of an interpretive approach, as this is customary in performance analysis. The primary aim of this approach is the hypothetical reconstruction of sense relations. In the process of interpretive reconstruction, certain data are interpreted as (observable) indicators of (unobservable, mental) translation strategies. These indicators represent the basis for the formation of hypotheses on the mental translation process. (A more detailed description of these phenomena is contained in Lörscher 1991: 56ff.)

The process of knowledge accumulation with respect to translation strategies has a dialectical nature. On the one hand, the analysts must have some knowledge of the concept of translation strategy in order to be able to ascribe the status of strategy indicators to certain signs. On the other hand, it is only by their indicators that translation strategies are constituted, so that knowledge of them can, to a very large extent, only be gained by means of strategy indicators. Therefore, the analysts must often proceed in a speculative and hypothetical way. They often do not interpret certain signs to be indicators as a result of their knowledge of the respective entity or of the relationship between an indicator and a segment of reality, but rather on the basis of considerations of probability. They can be corroborated or turn out to be false in the course of accumulating further knowledge of the phenomena and of gathering more experience in intepretation.

\section{A STRATEGIC ANALYSIS OF THE TRANSLATION PROCESS}

Translation strategies have been defined by me as procedures which the subjects employ in order to solve translation problems (Lörscher 1991: 76ff.). Accordingly, translation strategies have their starting-point in the realization of a problem by a subject, and their termination in a (possibly preliminary) solution to the problem or in the subject's realization of the insolubility of the problem at the given point in time. Between the realization of a translation problem and the realization of its solution or insolubility, further verbal and/or mental activities can occur which can be interpreted as being strategy steps or elements of translation strategies. They can be formalized to yield categories of a model for the strategic analysis of the translation process. Such a model was developed on the basis of a corpus of translations done by foreign language students. In the second stage of the project, it was applied to translations performed by professional translators. Modifications of the model were not necessary for an adequate analysis of professional translation processes although, as will be pointed out later, the quality and structure of the translation strategies and their elements, as well as their quantitative distribution, differ considerably, at least in part. The model consists of three hierarchical levels. The first and lowest contains those phenomena which can be interpreted to be elements of translation strategies, i.e. the smallest detectable problem-solving steps. The second level captures the manifestations of translation strategies, and the third and highest level comprises the translation versions. A detailed description of the model can be found in Lörscher (1991: 92ff.).

\section{Elements of Translation Strategies}

Elements of translation strategies can be distinguished as to whether they are original or potential. The former exclusively occur within strategic, i.e. problem-solving, 
phases of the translation process and are thus original elements of translation strategies. The latter also occur within non-strategic phases of the translation process. The following 22 elements of translation strategies could be found in my data corpus:

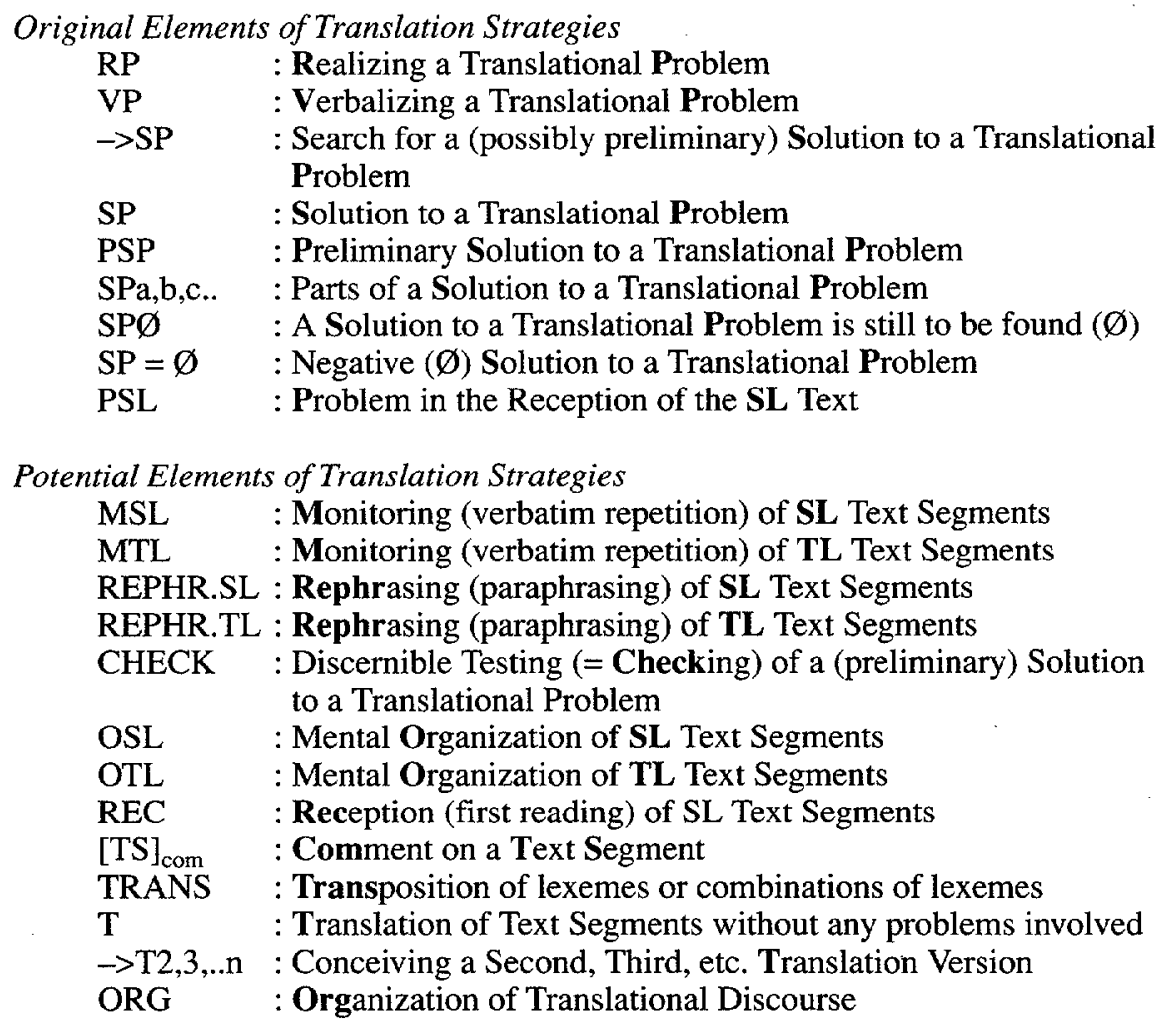

\section{Translation Strategies}

Translation strategies are procedures for solving translation problems. They are constituted by those minimal problem-solving steps I have just outlined. As the data show, the elements of translation strategies combine in specific ways only to build up structures. Accordingly, translation strategies contain one or more of these structures.

Following a model for the analysis of discourse, which I developed in a different context (Lörscher 1983), a distinction is made between basic structures, expanded structures, and complex structures of translation strategies. This is based on the fact that although translation strategies can be highly complex and thus difficult to document and describe in their manifold forms, they can be reduced to a fairly small number of simpler structures. The application of a generative principle allows the transformation of basic structures into expanded and complex structures. The types of translation strategies used by the subjects of my investigations are schematically represented below.

\section{Translation Strategies}

Five types of basic structures occur in my data corpus:

Type I : RP - (P)SP\#/SP

Type II $:$ RP $-\rightarrow$ SP - (P)SP\#/SP $\varnothing$ 
Type III : (RP) - VP - (P)SP\#/SP

Type IV : (RP) - ( $\rightarrow$ SP $)-$ VP $-(\rightarrow$ SP $)-($ P $)$ SP\#/SP ; at least one $\rightarrow$ SP must be realized.

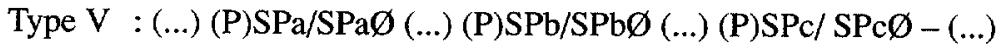

According to the generative principle, types II to IV can be derived from type I. Type II contains an additional phase of searching for a solution $(\rightarrow \mathrm{SP})$, type III contains an additional verbalization of the translational problem (VP), and type IV contains both an additional phase of searching ( $\rightarrow$ SP) and a verbalization (VP).

Expanded structures of translation strategies consist of a basic structure which contains one or more expansions. Expansions are defined as additional elements of a strategy itself. So, for example, the strategy RP - VP $\rightarrow$ SP - VP2 $\rightarrow$ SP - PSP contains a type IV structure, i.e. $\mathrm{RP}-(\rightarrow \mathrm{SP})-\mathrm{VP}-(\rightarrow \mathrm{SP})-(\mathrm{P}) \mathrm{SP}$, with two additional elements of the structure itself, (VP2, $\rightarrow$ SP), i.e. with two expansions.

Complex Structures are built up of several basic and/or expanded structures. An example may elucidate this. The strategy VP - SP $\varnothing-\rightarrow$ SP - PSP contains a type III and a type II structure. The former is terminated by SP $\emptyset$, i.e. with the subject leaving the problem aside in order to try and solve it later. The second part of the strategy is the realization of a type II structure. It terminates with a preliminary solution to the translation problem.

\section{Translation Versions}

As my data clearly show, the translation process contains both strategic phases, which are directed towards solving translational problems, and non-strategic phases, which aim at accomplishing tasks. The former range from the realization of a translational problem to its solution or to the realization of its insolubility at a given point in time. The latter start with the extraction of a unit of translation and terminate when it has been (preliminarily) rendered into TL or when a translational problem arises.

Translation versions are derived from a maxim which dominates an entire translation and according to which a translation should not merely convey the sense of the SL text into TL, but should be an adequate piece of discourse produced according to the $\mathrm{TL}$ norms of language use. Whereas translation strategies can, by definition, only occur within strategic phases of the translation process, translation versions can consist of strategic and/or non-strategic components. They can be located within strategies (i.e. intrastrategic versions), between strategies, and can range from one into another strategy. The latter case is called intraversional strategy.

As my data reveal, the subjects often produce several translation versions. They can comprise the entire text or only parts of it (e.g. paragraphs, sentences, clauses, or phrases). The production of several translation versions can have various reasons, of which at least four can be interpreted from the data:

i. If a subject does not succeed in solving a translational problem at the first attempt, $\mathrm{s} /$ he may try to solve the problem in its further context. This may require a second, third, etc. translation version which potentially also contains non-strategic parts of the translation.

ii. If, at the first attempt, a subject does not succeed in rendering a strategic or nonstrategic part of an SL text into TL in a way which is considered adequate, the subject may try to optimize the TL text production by conceiving a more adequate second, third, etc. translation version.

iii. If a subject, while checking a complex TL text segment, finds an alternative for it, s/he may conceive a further translation version which contains the alternative TL text segment plus part of its context. 
iv. If a subject translates a complex SL text segment consisting of several strategic and/or non-strategic parts by successively rendering its components into TL, the subject may produce a further version of the TL text segment. Thus, s/he may become aware of the complex interrelationships between the components of the TL text segment. S/he may realize that the components, in order to make an adequate stretch of TL discourse, cannot be put together in the same way as they were successively translated from the SL.

\section{PROFESSIONAL AND NON-PROFESSIONAL TRANSLATION PROCESSES: A SUMMARIZING COMPARISON}

The results of my empirical investigations which I have outlined so far are largely neutral with respect to whether professional or non-professional translators are concerned. As I pointed out at the beginning, I started my research with non-professional translators, mainly English-as-a-foreign-language-students, and then concentrated on professional translators. I did so for several reasons; one of them was to find out aspects of the development of translation competence from its very rudimentary beginnings to its elaborated forms ( $c f$. Lörscher 1992a).

In this section, I would like to briefly compare aspects of the translation processes of professionals and foreign language students and present the differences as they could be detected in or interpreted from the data available. Since the investigations are still in progress, the following considerations are of a preliminary kind. The first point I would like to make is that in spite of the differences, professional and non-professional translation processes have many features in common. The fact that the categories of my model of analysis, which were developed on the basis of non-professional translations, adequately capture professional translations, too, highly suggests that the two kinds of mental processes are similar, to say the least. From the point of view of the strategies detected, the mental processes of the two kinds of translators did not reveal significant differences. However, differences between professional translators and foreign language students can be detected in the distribution and frequency in the types of strategy, i.e. in the quantitative aspects of the translation strategies. Furthermore, the process-oriented approaches to the translations among the two groups of translators differ quite considerably.

1. Whereas most of the foreign language students take a mainly form-oriented approach to the translations, the professionals mainly employ sense-oriented procedures. Thus the shortcomings of translations with serious distortions of sense or violations of norms of target-language text production are avoided. More detailed considerations on this are contained in a recently published article by me (Lörscher 1992a).

2. The units of translation, i.e. the SL text segments which the subjects extract and put into their focus of attention in order to render them into the target-language as a whole, are considerably larger among professional translators than among foreign language students. In other words, the processing system of professionals can obviously handle larger units than that of non-professionals. The former mainly choose phrases, clauses or sentences as units of translation whereas the latter concentrate on syntagmas and especially on single words. As a consequence, professional translators often realize problems while they are rendering a unit of translation into the $\mathrm{TL}$. The foreign language students, however, mostly realize translation problems before they start translating because the units they extract from the SL text are much smaller and thus problems can be located more easily and more quickly. Furthermore, it is mainly problems of a local kind, especially lexical transfer 
problems arising from lack of competence in SL or TL, which the non-professionals are faced with whereas the professionals are primarily concerned with global, formulating problems, with the optimal expression of sense according to the TL norms of text production.

3. As I have pointed out elsewhere (Lörscher 1991), foreign language students tend not to ckeck those TL utterances according to their sense which they have translated and within which they did not realize any problem. As a consequence, the translations of the students more often than not reveal utterances which contain grammatical errors, even in their mother tongue, violations of TL text production norms, or which make no sense. Professional translators, however, tend to continuously check their TL text output, no matter whether it has been produced with or without any problems involved. So professional translators often do not realize formulating problems before they check their utterances produced in TL. This ex post realization of translation problems is an important distinguishing factor of professional vs. non-professional translation processes.

4. The professional translators mainly, though not exclusively, check their utterances produced in TL with regard to their stylistic and text-type adequacy. The foreign language students, by contrast, only check the solutions to their problems, and this checking is done with respect to lexical equivalence and, to a lesser extent, to their syntactic correctness. Stylistic and text-type adequacy play quite a subordinate role, if any, for them. Thus their translation processes are dominated, if not determined by the lexis and syntax of the SL text. As a result of this, texts in the target-language are produced which are often deficient and unacceptable because they contain violations of TL norms of text production. Such deficiencies can, at least in principle, be avoided by the different checking procedures generally employed by the professional translators.

\section{IMPLICATIONS FOR TRANSLATION TEACHING}

In this concluding section I want to raise the question in how far investigations into translation processes can contribute to the teaching of translation. Although this question cannot yet be answered finally, I would like to outline some of my thoughts on this problem.

To my mind, the main, if admittedly modest, merit of these investigations is that they have helped to locate, describe, and explain deficits in non-professional translating and have thus contributed to making us aware of aspects of the structure and of the complexities of translation.

To date, process-oriented research into translation has been purely descriptive, not prescriptive. Its principal aim has been to find out what actually goes on in the translators' heads, i.e. how they translate not how they should translate. The investigation of translation strategies has been carried out from the perspective of the subjects as hypothetically reconstructed by the analyst (Lörscher 1991). Thus, translation strategies are successful to the extent to which the subjects succeed in bringing about what to them are solutions to translation problems.

It is evident that what the subjects consider to be successful and what the analyst does often do not coincide. It is just as evident and can be documented empirically that subjects more often than not find target-language text segments which they consider to be solutions to problems but which apparently are translation errors. Nonetheless, such strategies are considered successful in view of the concept of success used in processoriented investigations. It would certainly be interesting and informative to compare what the subjects investigated consider to be success in their translation with what professional 
translators and/or bilingual informants would consider to be success. In this way, norms for evaluating translation strategies and ways of teaching successful strategies, in one way or other, could be developed. Although this is hardly more than a desideratum and goes beyond the scope of most of the process-oriented investigations, it is one, if not the most urgent, desideratum of research into translation processes at present.

\section{REFERENCES}

BÜHL, W. L. (Ed.) (1972): Verstehende Soziologie - Grundzüge und Entwicklungstendenzen, München.

ERICSSON, K. A. and H. A. SIMON (1984): Protocol Analysis. Verbal Reports as Data, Cambridge (MA).

GERLOFF, P. A. (1988): From French to English: A Look at the Translation Process in Students, Bilinguals, and Professional Translators, Mimeo, Harvard University.

JÄÄSKELÄINEN, R. H. (1990): Features of Successful Translation Processes: A Think-Aloud Protocol Study, Mimeo, University of Joensuu, Savonlinna School of Translation Studies.

KRINGS, H. P. (1986): Was in den Köpfen von Übersetzern vorgeht. Eine empirische Untersuchung der Struktur des Übersetzungsprozesses an fortgeschrittenen Französischlernern, Tübingen.

LÖRSCHER, W. (1983): Linguistische Beschreibung und Analyse von Fremdsprachenunterricht als Diskurs, Tübingen.

LÖRSCHER, W. (1991): Translation Performance, Translation Process, and Translation Strategies. A Psycholinguistic Investigation, Tübingen.

LÖRSCHER, W. (1992a): "Process-oriented Research into Translation and Implications for Translation Teaching", Traduction, Terminologie, Rédaction, V-1, pp. 145-161.

LÖRSCHER, W. (1992b): "Investigating the Translation Process", Meta, 37-3, pp. 426-439.

LÖRSCHER, W. (in preparation): Translation as Process. An Empirical Investigation into the Translation Process of Professionals, Bilinguals, and Foreign Language Learners.

MEHAN, H. and H. WOOD (1975): The Reality of Ethnomethodology, New York.

PSATHAS, G. (1972): "Verstehen, Ethnomethodologie und Phänomenologie", Bühl 1972, pp. 284-303.

SÉGUINOT, C. (Ed.) (1989): The Translation Process, Toronto.

TIRKKONEN-CONDIT, S. (Ed.) (1991): Empirical Research in Translation and Intercultural Studies, Tübingen. 